\title{
Review
}

\section{Invasion, spread, and vector potential of Aedes albopictus in the USA and its control possibilities}

\author{
Arshad Ali ${ }^{1)}$ and Jai K. NAYAR ${ }^{2)}$ \\ 1) University of Florida, IFAS, Central Florida Research and Education \\ Center, 2700 East Celery Avenue, Sanford, FL 32771-9608, USA \\ 2) University of Florida, IFAS, Florida Medical Entomology Laboratory \\ 200 9th Street, SE, Vero Beach, FL 32962-4657, USA
}

(Received: 22 October 1996; Accepted: 13 December 1996) \begin{abstract}
Key words: Aedes albopictus, Asian Tiger Mosquito, spread in the USA, control possi-
bilities
\end{abstract}
\begin{abstract}
Established populations of Aedes albopictus in the USA were first discovered in Texas, in 1985. Currently, Ae. albopictus has spread to at least 25 southeastern, mid-Atlantic and some mid-Western states in the continental USA. The introduction of $A e$. albopicitus in the USA seems to have occurred through used tires arriving from northern Asia. The rapid spread of Ae. albopictus in the USA has heightened human health concerns because of the known and potential vector relationships of Ae. albopictus with several arboviruses of public health importance. Thusfar, in the USA, four arboviruses have been isolated from specimens collected in Missouri, Florida, Texas, North Carolina, and Illinois. Among control methods, source reduction and public education and awareness of the biology and ecology of this mosquito are the primary targets. Biological control agents, such as predatory Toxorhynchites mosquitoes, species of copepods, and Bacillus thuringiensis serovar. israelensis (B.t.i.) have been tested and/or used in the field to reduce Ae. albopictus larvae. Use of repellents and other personal protection strategies against bites of $A e$. albopictus have been investigated. A laboratory study employing several organophosphates, pyrethroids, microbial pesticides (B.t.i. and Bacillus sphaericus) and insect growth regulators (IGRs), against larvae of a Florida laboratory population of $A e$. albopictus indicated the general toxicity ranking: IGRs $>$ pyrethroids $>$ OPs $>$ microbials. In a few laboratory and/or field studies, selected adulticides and larvicides (including time-release formulations) have shown good potential for the control of this mosquito. Mosquito adulticides, such as malathion, permethrin, Scourge $\circledast^{\circledR}$ (synergized resmethrin) and others used in various situations in the mid-Atlantic and southeastern United States, probably reduce populations of Ae. albopictus.
\end{abstract}

\section{INVASION AND SPREAD}

The Asian Tiger Mosquito, Aedes albopictus, reportedly got a firm foot-hold in the continental United States in the summer of 1985 when the Harris County Mosquito Control District in Houston, Texas, discovered breeding populations of this mosquito in its operational area (Sprenger and Wuithiranyagool, 1986). A preliminary survey of Harris County conducted in September 1985, indicated that Ae. albopictus was present in a wide variety of habitats, including water-filled used tires, flower pots in cemeteries, plastic pails, tin cans, and assorted rubbish containers within urban and rural environ- 


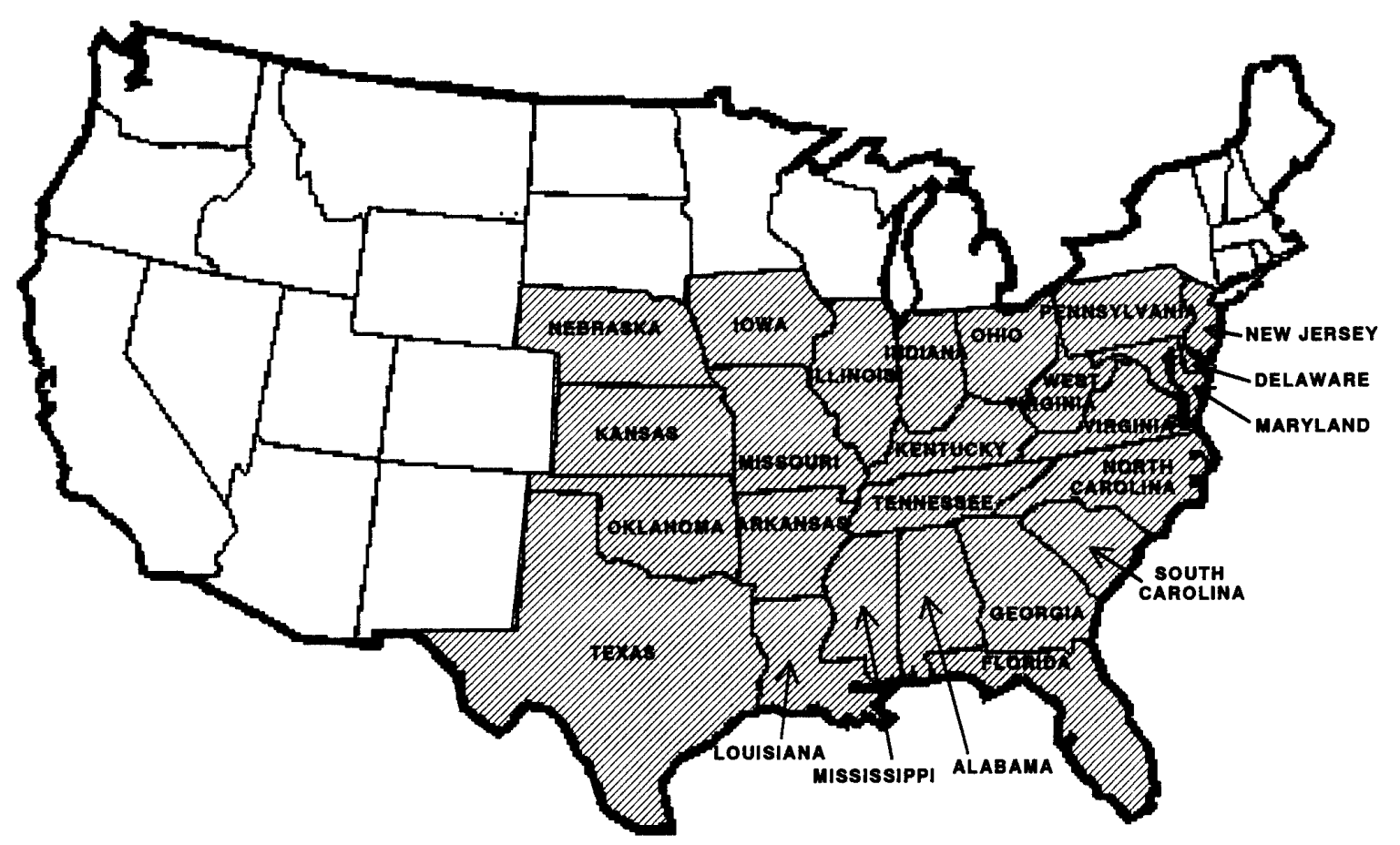

Fig. 1. Map of the continental United States of America with Aedes albopictus infested states shaded and labeled.

ments. It was found in $55.8 \%$ of 163 sites inspected. This was the first time that $A e$. albopictus was known to have become established in the Western hemisphere. It is likely that some populations of Ae. albopictus may have been established in the United States prior to 1985 and had escaped detection, because on several occasions dating back at least five decades, $A e$. albopictus had been collected in the United States (Pratt et al., 1946; Eads, 1972; Reiter and Darsie, 1984).

Aedes albopictus is a known vector of dengue in southeast Asia and has the potential to spread through both tropical and temperate regions of the Western hemisphere. Due to the potentially serious implications of Ae. albopictus in the United States, a group of local and national experts including members of the Harris County Mosquito Abatement District, the Texas State Health Department, and the Division of Vector-Borne Viral Diseases (DVBVD) of the Centers for Disease Control (CDC) visited the infested sites in Houston in March 1986 and discussed broadly the possible courses of action. As a result of these initial efforts, Ae. albopictus was found in 47 counties in 12 states (Anonymous, 1987).

It was originally hypothesized that $A e$. albopictus had most likely come to the United States through importation of used tire casings from Asian countries because of prior interceptions of this species in used military tires returned to the U.S. in 1946 and 1972 (Pratt et al., 1946; Eads, 1972). This hypothesis gained credence when it was shown that the importation of used tire casings from Asian countries, primarily Japan, for retreading in the U.S., was a major business (Reiter and Sprenger, 1987). Recent industry figures show that approximately 2 billion scrap tires are stock-piled in the USA and as many as 240 million additional scrap tires being generated each year (Lightsey, 1996). A DVBVD program established in 1986 to inspect used tire casings from Asia at ports of arrival in the U.S. revealed that $25 \%$ of the 22,000 individually inspected tires contained water when arriving in the USA. Used tires containing water are attractive oviposition sites for a number of 
mosquito species; even when dry on arrival at U.S. ports, such tires might well contain viable mosquito eggs (Eads, 1972). This mode of introduction was confirmed when larvae of Ae. albopictus were found in water-containing tires arriving at the port of Seattle, USA, from Tokyo, Japan (Craven et al., 1988). Since most strains of Ae. albopictus in the continental USA undergo a diapause in the egg stage, a characteristic of strains from temperate regions, it is highly probable that these strains were introduced in the United States from northern Asia, most likely Japan.

In addition to international movement of used tires, intra- and interstate transport of discarded tires within the United States has provided a means for the dissemination of Ae. albopictus in the continental USA (Reiter and Sprenger, 1987). Since its initial discovery in Texas in 1985, Ae. albopictus has presently (1996) spread to 25 contiguous states (Fig. 1) covering the entire southeastern, midAtlantic and some mid-western USA (C. G. Moore, pers. commun.). This rather rapid spread of Ae. albopictus within the USA is again attributable primarily to commerce in used and scrap tires because adult $A e$. albopictus are relatively short fliers, 200 yards was the maximum distance flown in tests conducted in Hawaii (Bonnet and Worcester, 1946); therefore, flight may be relatively unimportant in the dispersal of this species.

In Florida, Ae. albopictus was first discovered in the northern part of the state (Jacksonville) in 1986 (Peacock et al., 1988) and over the following 8 years (summer 1994) it had spread to all 67 counties of the state (O'Meara et al., 1995). The initial occurrence and subsequent spread of this species at the county level in some counties of Florida have been reported [e.g., Ansell (1994), Betts (1994), Sibal (1994), Hornby and Miller (1994), and Hornby and Opp (1994)]. Although used tires have been considered the major habitat of im. mature $A e$. albopictus in the state where more than 12 million waste tires are generated each year (O'Meara and Gettman, 1992), flower-holding containers at cemeteries also have been shown to support significantly large populations of this mosquito (O'Meara et al., 1992). Other common man-made habitats for immature Ae. albopictus include bird baths, water bowls for pets, buckets, plates under potted plants, clogged rain gutters and flower vases. Natural containers, such as tree holes and tank bromeliads also provide suitable habitats for immature $A e$. albopictus. Currently, populations of $A e$. albopictus are very common throughout north Florida, widely but sparsely distributed in the central part of the state, and relatively rare in south Florida (O'Meara et al., 1993). In some parts of the state, major declines in the abundance of Ae. aegypti have been associated with the expansion of Ae. albopictus in both urban and rural settings (O'Meara et al., 1995).

\section{Medical Significance}

Shroyer (1986) and Mitchell (1991, 1995) have provided reviews of vector competence studies involving Ae. albopictus. In these reviews, this mosquito has been shown to be a competent experimental vector of seven Alphaviruses [chickungunya (CHIK), eastern equine encephalitis (EEE), Mayaro (MAY), Ross River (RR), western equine encephalitis (WEE), Venezuelan equine encephalitis (VEE), and Sindbis (SIN)]. CHIK and RR viruses are not found in North America. Regarding EEE and WEE, it seems unlikely that $A e$. albopictus will become a major vector of these viruses in the USA unless a significant degree of feeding on birds occurs. Also, WEE virus activity generally occurs in dry and semi-arid areas of the Great Plains and Western United States, areas unfavorable in terms of humidity levels needed for Ae. albopictus in nature. Regarding VEE and MAY viruses, the current distribution of Ae. albopictus in Texas overlaps with areas that experienced epizootic 
VEE activity during 1971. Aedes albopictus is not present in areas where MAY epidemics have occurred.

Among Flaviviruses, Ae. albopictus can experimentally transmit Dengue (DEN) serotypes 1, 2, 3, and 4, Japanese encephalitis (JE), West Nile (WN), and yellow fever (YF) viruses (Mitchell, 1995). An additional Flavivirus, St. Louis encephalitis (SLE) virus, does not readily infect $A e$. albopictus at doses that normally would be encountered in nature (Savage et al., 1994). Because of concern that Ae. albopictus might become involved in the transmission cycle of dengue (DEN) viruses in the Americas, vector competence studies with these viruses have been conducted (Boromisa et al., 1987; Mitchell et al., 1987). Per os infection rates and transmission rates indicate that the Houston strain of Ae. albopictus is competent experimental vector of each DEN serotype. The DEN-1 virus transmission rates reported from Houston Ae. albopictus ranged from 38\% (Boromisa et al., 1987) to 88\% (Mitchell et al., 1987). Studies conducted at the CDC show that the Houston strain of Ae. albopictus is a competent vector of yellow fever (YF) virus. In view of the adaptation of Ae. albopictus to peridomestic habitats, this mosquito has the potential to bridge the gap between jungle and urban YF cycles in the Western Hemisphere (Mitchell et al., 1987).

Eight Bunyaviridae included in vector competence tests with Ae. albopictus have been shown to infect by the oral route: Jamestown Canyon (JC), Keystone (KEY), La Crosse (LAC), Oropouche (ORO), Potosi (POT), Rift Valley fever (RVF), San Angelo (SA), and trivittatus (TVT) viruses (Mitchell, 1995). With the exception of KEY, ORO, and TVT viruses, all of these viruses are transmitted efficiently by bite. In addition, KEY, LAC, and SA viruses can be transmitted vertically under experimental conditions (Mitchell, 1995). A major concern regarding the establishment of $A e$. albopictus in the United States has been the possibility that this mosquito may become involved in the transmission cycle of LAC virus. Grimstad et al. (1989) showed that 3 geographic strains of $A e$. albopictus from the United States are competent vectors for LAC virus and the mosquito occurs within the range of LAC virus activity (Wesson et al., 1990). Three other Bunyaviruses, JC, KEY, and TVT were generally inefficient (Grimstad et al., 1989).

Since the discovery of Ae. albopictus establishment in the USA (1985), the CDC has been testing field-collected Ae. albopictus from several areas of the USA for the presence of arboviruses. So far, four viruses, POT (Francy et al., 1990; Mitchell et al., 1990), EEE and KEY (Mitchell et al., 1992), and TEN (Mitchell et al., 1992) have been isolated from Ae. albopictus collected in Florida, Illinois, Missouri, North Carolina, and Texas (Mitchell, 1995).

In 1995, seven locally-acquired human cases of Dengue were recorded as having occurred in Texas (Anonymous, 1996). All of these cases were confined to two counties in southern Texas immediately north of Mexico where a dengue outbreak was in progress. Of these, three cases consisted of patients exhibiting 4-fold increases in antibody titers to DEN virus, and 4 probable cases, with $<4$-fold increase in antibody titer, but otherwise exhibiting the classical symptoms of Dengue. DEN 2 and DEN 4 viruses were isolated from one resident in each county. Two other confirmed and 3 probable cases were also reported from these counties, but each of the subjects involved had a history of recent travel to Dengue-affected areas of Mexico. From other areas of Texas, a total of 16 additional confirmed or probable cases of Dengue were reported during 1995, with all these cases having histories of recent travel to Dengue-affected areas of Mexico or to other countries where the disease is endemic. One case from Dallas was an adult male from whom DEN 3 virus was isolated and this person had recently returned from a surface trip through central America and Mexico (Anonymous, 1996). 
Aedes albopictus has not yet been implicated as a vector of dengue in the USA and to date remains primarily a biting nuisance in the country.

\section{Control Attempts and Possibilities}

Source reduction: Due to the scattered nature and large diversity of habitats of immature Ae. albopictus as well as a wide variation of habitat size ranging from a few drops of water in a discarded candy wrapper to larger amounts of rain water accumulated in used tires of various sizes, the best approach to control this mosquito is to eliminate larval habitats. Educational programs including distribution of materials which inform citizens about the important role they can play to prevent mosquito production from various containers around their homes and at cemeteries (flower vases and urns) are in place in various states, especially Florida. Such materials are distributed at fairs, schools, and large events such as retirement expos, garden shows, etc. The Florida Comprehensive Solid Waste Act of 1988 (and subsequent amendments) led to legislation regulating waste tire storage and disposal in Florida. As of July 1, 1989, outdoor accumulation of more than 1,000 waste tires (except at a permitted processing facility) is prohibited in Florida. Except where exempt by rule, most persons accumulating fewer tires must obtain a state permit which identifies the location and requires minimum storage standards including mosquito control. Also, waste tires must be shredded before being disposed in local landfills. Transport of more than 25 tires at one time requires a permit with approved destination storage and disposal plans. The law provides for a surcharge on all new tire purchases to facilitate waste tire disposal costs. Under the state litter law, dumping of waste tires in Florida is a felony offense. However, current requirements for the storage of waste tires are grossly inadequate for mosquito abatement and the Waste Tire
Rule needs revision to require storage of all tires under cover (O'Meara and Gettman, 1992). At the Federal level, continued introduction of Ae. albopictus in the USA is being prevented since January 1 , 1988, under the provisions of Public Law $78-410$, which requires that all used tire casings coming from Asia be certified as dry, clean, and free of insects. Tire casings coming from an Ae. albopictus infested area can be treated by heat. Fifteen minutes exposure to $46.1^{\circ} \mathrm{C}$ (dry or steam) was $100 \%$ lethal to all aquatic stages of $A e$. albopictus (Smith et al., 1988). Fumigation with methyl bromide (ca. $32 \mathrm{~g} / \mathrm{m}^{3}$ for $24 \mathrm{~h}$ ) will kill all stages of Ae. albopictus as long as the tires are dry, but methyl bromide will not kill eggs submerged in water unless very high doses are used (Anonymous, 1987). Thus, it is imperative that tires be dry before fumigation.

Achieving permanent mosquito control in natural containers, such as tree holes and terrestrial bromeliads are more difficult. Tree holes are filled and blocked where possible. In some situations, a water absorbent polymer to prevent mosquito production around homes in urban locations is applied (J. Stewart, pers. commun.). Homeowners are advised to limit the number of tank bromeliads in their yards. Mosquito and plant debris can be flushed out of these plants twice a week with a garden hose equipped with an appropriate nozzle. Growing bromeliads in plastic pots makes it easier to flush out the mosquitoes (O'Meara and Gettman, 1992). Chemical and microbial mosquito larvicides in natural habitats may provide temporary control, but generally are not cost effective.

Biological control: Among biological control possibilities of Ae. albopicus in the USA, the gregarine protozoan, Ascogregarina taiwanensis was reported to infect $A e$. albopictus in Illinois; infection rates were $67-95 \%$ at one site and $0-10 \%$ at another (Munstermann and Wesson, 1990). In Louisiana and Florida, several species of cyclopoid copepods have been field-tested 
for reducing Ae. albopictus populations. In Louisiana, Macrocyclops albidus and Mesocyclops longisetus were the most effective, reducing $A e$. albopictus larvae by $99 \%$ within 6-8 weeks post-introduction to tires (Marten, 1990a). In another study, Ae. albopictus were completely eliminated from tire piles in 2 months by Macrocyclops albidus introduction (Marten, 1990b). Mesocyclops longisetus was successfully evaluated in tire piles in the panhandle of Florida where it overwinters and showed promise for the biological control of container breeding mosquitoes (Schreiber et al., 1993). Some of these copepods require serious consideration for further development and use in operational control programs of Ae. albopictus in the USA. Field studies on the establishment of breeding populations of Toxorhynchites splendens and its ability to control containerbreeding mosquitoes in Tampa Bay area of Florida gave mixed results. This predator mosquito effectively colonized experimental containers in the immediate vicinity of the adult releases, but no evidence of its long-range ( $>1$ mile) dispersal was detected. Although $T$. splendens effectively reduced prey populations of mosquitoes in experimental containers, it failed to establish a continuously breeding population at any release site, necessitating its reintroduction (J. Cuda, personal commun.). The fungal pathogen Lagenidium giganteum was ineffective as a control agent for $A e$. albopictus in used tires in the field (Becnel et al., 1996). The microbial mosquito larvicide, Bacillus thuringiensis serovar. israelensis (B.t.i.) in various formulations, has been successfully used in some situations for the local eradication or control of $A e$. albopictus (Jardina, 1990; Cilek et al., 1989; Nasci et al., 1994; Becnel et al., 1996).

Chemical control: There are a few laboratory and/or field studies on the chemical control of larvae and adults of U.S. strains of Ae. albopictus. Use of repellents and other personal protection strategies against bites of a Jacksonville, FL, strain of Ae. albopictus were studied by Schreck and McGovern (1989). Among several evaluated repellents, products containing $\geq 12 \%$ deet (diethyl methylbenzamide) were considered to provide satisfactory protection against Ae. albopictus. Clothing fabric treated with permethrin $(40 \%$ emulsifiable concentrate) at the rate of $0.125 \mathrm{mg} \mathrm{AI} / \mathrm{cm}^{2}$ cloth, provided complete protection against bites of Ae. albopictus even after 5 launderings. Regarding $A e$. albopictus larviciding and adulticiding studies, Peacock et al. (1988) used larviciding oil (Florida Mosquito Larvicide), and mixture of B.t.i. and permethrin to control Ae. albopictus in northern Florida; thermal fogging with Dibrom ${ }^{\circledR}$ (naled) in diesel fuel were also employed to achieve adequate control. Khoo et al. (1988) evaluated malathion, Scourge ${ }^{\circledR}$ (synergized resmethrin) and bendiocarb against laboratory colonized and wild caught Ae. albopictus adults in Texas. The test populations were resistant to malathion as the mortalities ranged from $33-100 \%$ when exposed to doses ranging from 10-100 ng/ o ; generally $<100 \%$ mortality was achieved at 100 $\mathrm{ng} /$ ㅇ for several populations. In contrast, Scourge ${ }^{\circledR}$ was highly effective, yielding $100 \%$ adult mortality at $3 \mathrm{ng} /$ 우, and bendiocarb was moderately active resulting in $3-20 \%(24 \mathrm{~h}), 15-32 \%(48 \mathrm{~h})$, and $30-$ $45 \%(72 \mathrm{~h})$ adult mortalities at doses ranging from 3-10 ng/ㅇ․ Robert and Olson (1989) reported $\mathrm{LC}_{95}$ of $0.14-0.17 \mu \mathrm{g} / \mathrm{vial}$ (bendiocarb), $1.61-4.65 \mu \mathrm{g} / \mathrm{vial}$ (malathion), $0.13-0.35 \mu \mathrm{g} / \mathrm{vial}$ (naled), and $0.12-$ $0.13 \mu \mathrm{g} /$ vial (resmethrin) for 2 wild Texas strains of Ae. albopictus, confirming some levels of resistance to malathion. However, adult female Ae. albopictus reared from larvae collected from the Lower Rio Grande Valley of Texas and Mexico were considered to be susceptible to malathion, chlorpyrifos, resmethrin and permethrin (Sames et al., 1996). Cilek et al. (1989) reported $L C_{90}$ values of 0.3841 for malathion and 0.0043 for permethrin for a Kentucky strain of Ae. albopictus and successfully used ULV Scourge ${ }^{\circledR}$, B.t.i. and Aurosurf ${ }^{\circledR}$ (monomolecular surface film) to lo- 
cally eradicate Ae. albopictus (immature and adult) populations. Nasci et al. (1994) tested time-release Abate ${ }^{\circledR}$ (temephos) pellets, and Altosid $®$ (methoprene) sand and pellet formulations against $A e$. albopictus in clay flower bowls in the field in Louisiana. In these tests, temephos and methoprene provided $100 \%$ control of $A e$ albopictus for 150 days, and the authors concluded that long-term control of Ae. albopictus populations can be achieved economically with one application of Altosid or Abate pellets in containers. In another study in waste tires in Florida, a slowrelease pellet formulation of Altosid provided almost complete control of $A e$. $a l b$ opictus for 116 days (Becnel et al., 1996). Morris et al. (1996) employed a very wide range of temephos granules (0.11-22.42 $\mathrm{kg} \mathrm{AI} / \mathrm{ha}$ ) for Ae. albopictus control in waste tires in Florida and reported immediate control (98\%) at $0.56 \mathrm{~kg} \mathrm{AI} / \mathrm{ha}$ and $100 \%$ control for at least 5 months at $11.21 \mathrm{~kg} \mathrm{AI} / \mathrm{ha}$. In a recent laboratory study, Ali et al. (1995) evaluated 5 organophosphates (OPs) (chlorpyrifos, chlorpyrifos methyl, fenthion, malathion, and temephos), 3 pyrethroids (bifenthrin, cypermethrin, and permethrin), B.t.i., and Bacillus sphaericus against a Florida Ae. albopictus population colonized in the laboratory. In addition, 3 insect growth regulators (IGRs) (diflubenzuron, methoprene, and pyriproxyfen) were evaluated. All OPs, except for malathion, were highly effective as indicated by low $\mathrm{LC}_{90 \text { s }}$ ranging from $0.0069 \mathrm{ppm}$ (chlorpyrifos) to 0.026 ppm (fenthion); the larvae were considered tolerant to malathion $\left(\mathrm{LC}_{90}=1.043 \mathrm{ppm}\right)$. $\mathrm{LC}_{90}$ values of pyrethroids were: 0.0175 ppm (bifenthrin), 0.0079 ppm (cypermethrin), and $0.0031 \mathrm{ppm}$ (permethrin). Commercial products of B.t.i., Vectobac ${ }^{\circledR}$ and Bactimos ${ }^{\circledR}$ were considered economically effective against $A$ e. albopictus larvae, but products of $B$. sphaericus were ineffective $\left(\mathrm{LC}_{90 \mathrm{~s}}>28 \mathrm{ppm}\right)$. IGRs showed exceptional activity. Pyriproxyfen $\quad\left(\mathrm{LC}_{90}=0.000376\right.$ ppm), was 2.23 and 21.5 times more effective than diflubenzuron and methoprene, respectively. In general, toxicity ranking of chemicals and microbials tested was: IGRs $>$ py rethroids $>$ OPs $>$ microbials.

Although B.t.i., several OP insecticides, pyrethroids, and IGRs are highly effective against Ae. albopictus strains in North America, emphasis at the mosquito abatement district level in the Ae. albopictus infested areas in the United States is placed on source reduction through various means to discourage breeding of this mosquito. Mosquito adulticides, such as malathion, permethrin, chlorpyrifos, Dibrom ${ }^{\circledR}$, Scourge ${ }^{\circledR}$, and others routinely used for mosquito control in the midAtlantic and southeastern United States, probably reduce populations of Ae. albopictus. The larvae of this species are successfully targeted in some states by the use of temephos and B.t.i. in various formulations. However, these control measures are employed as a supplement to source reduction efforts.

\section{ACKNOWLEDGMENT}

This is Florida Agricultural Experiment Stations Journal Series No. R-05563.

\section{REFERENCES}

Ali, A., J. K. Nayar and R. D. Xue (1995) Comparative toxicity of selected larvicides and insect growth regulators to a Florida laboratory population of Aedes albopictus. J. Am. Mosq. Control Assoc., 11: 72-76.

Anonymous (1987) Aedes albopictus in the Americas: Biology, distribution, and public health importance. Div. Vector-Borne Viral Dis., Centers for Disease Control, 7 pp., Ft. Collins, CO.

Anonymous (1996) Dengue outbreak-1995, South Central States Region. Soc. Vector Ecol., Newsletter, 27: 1-16.

Ansell, W. (1994) Aedes albopictus in the Gulf Mosquito Control District, Bay County, FL. J. Florida Mosq. Control Assoc., 65: 20.

Becnel, J. J., J. Garcia and M. Johnson (1996) Effects of three larvicides on the production of Aedes albopictus based on removal of pupal exuviae. J. Am. Mosq. Control Assoc., 12: 499-502. 
Betts, R. R. (1994) Aedes albopictus and Aedes aegypti -Species domination in St. Johns County. J. Florida Mosq. Control Assoc., 65: 17-19.

Bonnet, D. D. and D. J. Worcester (1946) The dispersal of Aedes albopictus in the territory of Hawaii. Am. J. Trop. Med., 26: 465-476.

Boromisa, R. D., K. S. Rai and P. R. Grimstad (1987) Variation in the vector competence of geographic strains of Aedes albopictus for dengue 1 virus. $J$. Am. Mosq. Control Assoc., 3: 378-386.

Cilek, J. E., G. D. Moorer, L. A. Delph and F. W. Knapp (1989) The Asian tiger mosquito Aedes albopictus in Kentucky. J. Am. Mosq. Control Assoc., 5: 267268.

Craven, R. B., D. A. Eliason, D. B. Francy, P. Reiter, E. G. Campos, W. L. Jacob, G. C. Smith, C. J. Bozzi, C. G. Moore, G. O. Maupin and T. P. Monath (1988) Importation of Aedes albopictus and other exotic mosquito species into the United States in used tires from Asia. J. Am. Mosq. Control Assoc., 4: 138-142.

Eads, R. B. (1972) Recovery of Aedes albopictus from used tires shipped to United States ports. Mosq. News, 32: 113-114.

Francy, D. B., N. Karabatsos, D. M. Wesson, C. G. Moore, Jr., J. S. Lazuick, M. L. Niebylski, T. F. Tsai and G. B. Craig, Jr. (1990) A new arbovirus from Aedes albopictus, an Asian mosquito established in the United States. Science, 250: 1738-1740.

Grimstad, P. R., J. F. Kobayashi, M. Zhang and G. B. Craig, Jr. (1989) Recently introduced Aedes albopictus in the United States: Potential vector of La Crosse virus (Bunyaviridae: California serogroup). J. Am. Mosq. Control Assoc., 5: 422-427.

Hornby, J. A. and T. W. Miller, Jr. (1994) Aedes albopictus distribution abundance and colonization in Lee County, Florida, and its effect on Aedes aegypti -two additional seasons. J. Florida Mosq. Control Assoc., 65: 21-27.

Hornby, J. A. and W. R. Opp (1994) Aedes albopictus distribution, abundance and colonization in Collier County, Florida, and its effect on Aedes aegypti. J. Florida Mosq. Control Assoc., 65: 28-34.

Jardina, B. J. (1990) The eradication of Aedes albopictus in Indianapolis, Indiana. J. Am. Mosq. Control Assoc., 6: 310-311.

Khoo, B. K., D. J. Sutherland, D. Sprenger, D. Dickerson and H. Nguyen (1988) Susceptibility status of Aedes albopictus to three topically applied adulticides. J. Am. Mosq. Control Assoc., 4: 310-313.

Lightsey, D. (1996) Tire recycling: Marketing our neglected resources. Am. Mosq. Control Assoc., Newsletter, 22 (July-August): 6-13.

Marten, G. G. (1990a) Evaluation of cyclopoid copepods for Aedes albopictus control in tires. J. Am. Mosq. Control Assoc., 6: 681-688.

Martin, G. G. (1990b) Elimination of Aedes albopictus from tire piles by introducing Macrocyclops albidus (Copepoda: Cyclopoidae). J. Am. Mosq. Control Assoc., 6: 689-693.

Mitchell, C. J. (1991) Vector competence of North and South American strains of Aedes albopictus for certain arboviruses. J. Am. Mosq. Control Assoc., 7: 446-451.

Mitchell, C. J. (1995) Geographic spread of Aedes albopictus and potential for involvement in arbovirus cycles in the Mediterranean basin. J. Vector Ecol., 20: $44-58$.

Mitchell, C. J., B. R. Miller and D. J. Gubler (1987) Vector competence of Aedes albopictus from Houston, Texas, for dengue serotypes 1 to 4 , yellow fever, and Ross River viruses. J. Am. Mosq. Control Assoc., 3: 460-465.

Mitchell, C. J., M. L. Niebylski, G. C. Smith, N. Karabatsos, D. Martin, J. P. Metebi, G. B. Craig, Jr. and M. J. Mahler (1992) Isolation of eastern equine encephalitis from Aedes albopictus in Florida. Science, 257: 526-527.

Mitchell, C. J., G.C. Smith and B. R. Miller (1990) Vector competence of Aedes albopictus for a newly recognized Bunyavirus from mosquitoes collected in Potosi, Missouri. J. Am. Mosq. Control Assoc., 6: 523-527.

Morris, C. D., D. A. Dame and J. W. Robinson (1996) Control of Aedes albopictus in waste tire piles with reduced rates of temephos-treated granules. J. Am. Mosq. Control Assoc., 12: 472-476.

Munstermann, L. E. and D. M. Wesson (1990) First record of Ascogregarina taiwanensis (Apicomplexa: Leaudinidae) in North American Aedes albopictus. J. Am. Mosq. Control Assoc., 6: 235-243.

Nasci, R., G. R. Wright and F. S. Willis (1994) Control of Aedes albopictus larvae using time-release larvicide formulations in Louisiana. J. Am. Mosq. Control Assoc., 10: 1-6.

O'Meara, G. F. and A. D. Gettman (1992) The Asian Tiger Mosquito in Florida. Univ. Florida, Mosq. Control Fact Sheet, FMEL, Vero Beach, FL: 1-4.

O'Meara, G. F., L. F. Evans, Jr., A. D. Gettman and J. P. Cuda (1995) Spread of Aedes albopictus and decline of Ae. aegypti (Diptera: Culicidae) in Florida. J. Med. 
Entomol., 32: 554-562.

O'Meara, G. F., A. D. Gettman, L. F. Evans, Jr. and F. D. Scheel (1992) Invasion of cemeteries in Florida by Aedes albopictus. J. Am. Mosq. Control Assoc., 8: 1-10.

O'Meara, G. F., A. D. Gettman, L. F. Evans, Jr. and G. A. Curtis (1993) The spread of Aedes albopictus in Florida. Am. Entomol., 39: 163-172.

Peacock, B. E., J. P. Smith, P. G. Gregory, T. M. Loyless, J. A. Mulrennan, Jr., P. R. Simmonds, L. Padgett, Jr., E. K. Cook and T. R. Eddins (1988) Aedes albopictus in Florida. J. Am. Mosq. Control Assoc., 4: 362-365.

Pratt, J. J., R. H. Helenick, J. B. Harrison and L. Haber (1946) Tires as a factor in the transportation of mosquitoes by ships. Milit. Surg., 99: 785-788.

Reiter, P. and R. F. Darsie, Jr. (1984) Aedes albopictus in Memphis, Tennessee (USA): An achievement of modern transportation? Mosq. News, 44: 396-399.

Reiter, P. and D. Sprenger (1987) The used tire trade: A mechanism for the worldwide dispersal of container breeding mosquitoes. J. Am. Mosq. Control Assoc., 3: 494-501.

Robert, L. L. and J. K. Olson (1989) Susceptibility of female Aedes albopictus from Texas to commonly used adulticides. J. Am. Mosq. Control Assoc., 5: 251-253.

Sames, IV, W. J., R. Bueno, Jr., J. Hayes and J. K. Olson (1996) Insecticide susceptibility of Aedes aegypti and Aedes albopictus in the Lower Rio Grande Valley of Texas and Mexico. J. Am. Mosq. Control Assoc., 12: 487-490.

Savage, H. M., G. C. Smith, C. J. Mitchell, R. G. McLean and M. V. Meisch (1994) Vector competence of Aedes albopictus from Pine Bluff, Arkansas, for St. Louis encephalitis virus strain isolated during the 1991 epidemic. J. Am. Mosq. Control Assoc., 10: 501-506.

Schreck, C. E. and T. P. McGovern (1989) Repellents and other personal protection strategies against Aedes albopictus. J. Am. Mosq. Control Assoc., 5: 247-250.

Schreiber, E. T., W. L. Turner, III, A. M. Lopez, C. F. Hamilton and G. G. Marten (1993) Evaluation of two cyclopoid copepods for Aedes albopictus control in tires in the panhandle of Florida at low introduction rates. J. Florida Mosq. Control Assoc., 64: 73-77.

Shroyer, D. A. (1986) Aedes albopictus and arboviruses: A concise review of the literature. J. Am. Mosq. Control Assoc., 2: 424-428.

Sibal, H. I. (1994) Aedes albopictus and Ae. aegypti in Polk County. J. Florida Mosq. Control Assoc., 65: 15-16.

Smith, G. C., D. A. Eliason, C. G. Moore and E. N. Ihenacho (1988) Use of elevated temperatures to kill Aedes albopictus and Ae. aegypti. J. Am. Mosq. Control Assoc., 4: 557-558.

Sprenger, D. and T. Wuithiranyagool (1986) The discovery and distribution of Aedes albopictus in Harris County, Texas. J. Am. Mosq. Control Assoc., 2: $217-219$

Wesson, D., W. Hawley and G. B. Craig, Jr. (1990) Status of Aedes albopictus in the Midwest: La Crosse belt distribution, 1988. Proc. Ill. Mosq. and Vector Control Assoc., 1988, 1: 11-15. 